\title{
Espaços culturais de Teresina-PI: cotidiano, memórias e sociabilidades (décadas de 1980 e 1990)'
}

\author{
Raimundo Nonato Lima dos Santos*
}

\section{Introdução}

A cidade de Teresina, capital do Piauí, fundada em 1852, constitui-se como uma das primeiras cidades planejadas do Brasil (Abreu, 2000). Nas décadas de 1930 e 1940, ela tomou contornos de uma cidade moderna por meio de uma "limpeza urbana", que retirou do centro da cidade as casas com cobertura de palha, além de outros melhoramentos urbanísticos que já se processavam desde o início da Primeira República (Nascimento, 2015). Também conhecida como "Cidade Verde”, essa urbe recebeu (e ainda recebe), desde sua fundação, migrantes de várias partes do interior do Piauí, bem como de outros estados brasileiros, dentre

* Doutor em História pela UFPE; Professor do curso de História da Universidade Federal do Piauí (UFPI)/Campus Senador Helvidio Nunes de Barros (CSHNB); Docente Orientador no Programa de Residência Pedagógica. Assessor de Açôes de Extensão e Cultura da UFPI/CSHNB. Coordenador dos Projetos de Pesquisa do Programa Institucional de Bolsas de Iniciação Científica (PIBIC) e do Programa Institucional de Iniciação Científica Voluntária (ICV): "Cidade, música e história: representações urbanas no rock brasileiro dos anos de 1980 e 1990" (2018-2019); "Cidades sensíveis e imaginárias: representaçốes do viver urbano em cidades brasileiras, nas décadas de 1980 e 1990" (2019-2020); Coordenador do Projeto de Extensão TEMPUS (Teatro Experimental Universitário em Estudos Históricos); Membro do Grupo de Pesquisa do CNPQ "Cidade, Tempo e Espaço"; Organizador do livro "Cidades brasileiras" (coleção As cidades de Clio: abordagens históricas sobre o urbano (2019), ISBN: 978-85-509-0474-0. E-mail: raimundolima2011@ufpi.edu.br.

1 O texto constitui-se como o último tópico, do segundo capítulo, de minha tese de doutorado, "Praticando espaços, entre acordes, letras e máscaras: história, memória e sociabilidades em espaços culturais de Teresina nas décadas de 1980 e 1990", defendida na Universidade Federal de Pernambuco (UFPE) em novembro de 2016. 
os quais se destacam o Maranhão e o Ceará (Araújo, 2006).

Na década de 1950, o estado do Piauí se integrou ao contexto nacional de urbanização. Houve um crescimento industrial e comercial que contribuiu para o aumento populacional nas principais cidades do estado como Teresina, Picos, Parnaíba e Floriano. A partir dos anos 1960 há uma integração com a política nacional de habitação, ligada ao BNH (Banco Nacional de Habitação). Nas três décadas seguintes há um significativo crescimento horizontal da capital piauiense, com a emergência de diversos conjuntos habitacionais e de vilas e favelas. No final dos anos 1980 e meados de 1990 a cidade vai se verticalizando e se percebe uma redução das habitaçôes precárias, derivado em parte das políticas públicas habitacionais do município (Façanha, 2004).

Cabe ressaltar que essas políticas públicas habitacionais não foram suficientes para resolver o grande déficit habitacional de Teresina, agravado pelo crescente êxodo rural. E, aliado a isso, havia altos índices de desemprego, de analfabetismo e poucos investimentos no setor cultural e educacional (Lima, 2014). Apesar desse cenário desordenado, o teresinense, em suas práticas cotidianas, em espaços públicos e privados, desenvolvia variadas formas de lazer e sociabilidade.

Diante do exposto, apresentamos um texto que analisa as práticas cotidianas em espaços culturais da cidade de Teresina, capital do Piauí, desenvolvidas por teresinenses, com foco nos artistas locais, nas décadas de 1980 e 1990. Além disso, interpreta a forma como esses artífices se relacionavam com os locais indicados e avalia a importância desses espaços culturais para os artistas da cidade.

O campo temático da pesquisa se enquadra na História das Cidades, na perspectiva da Nova História Cultural, que concebe a cidade como um problema e um objeto de reflexão, onde se pode trabalhar com o imaginário urbano, fazendo análises de discursos e imagens de representaçáo da cidade, que refletem espaços, atores e práticas sociais.

A narrativa foi construída com base em variadas fontes, que incluem jornais, crônicas e relatos orais. A análise dessas fontes foi discutida em duas partes, sendo que a primeira apontou a Feira Popular de Arte, o Teatro de Arena, o Verdão e o Auditório Herbert Parentes Fortes como espaços públicos cujas atividades estavam atreladas aos projetos culturais empreendidos pela iniciativa pública, municipal e/ou estadual. Na segunda parte, ampliamos nosso olhar para os bares, concebendo-os como espaços culturais alternativos, que tinham sua dinâmica e clientela própria e que estavam mais presentes no cotidiano dos teresinenses. $\mathrm{O}$ que ficou evidente em nosso estudo é que esses dois conjuntos de lugares se configuraram como espaços de lazer e de entretenimento cultural para uma parcela significativa da sociedade teresinense. 


\section{Espaços públicos e projetos culturais}

A Feira Popular de Arte $^{2}$ foi um projeto cultural da Secretaria de Cultura, Desportos e Turismo do Governo do Estado do Piauí, desenvolvido na década de 1980. O projeto teve início na Praça Saraiva, no centro da cidade de Teresina, onde era realizado aos domingos, logo depois se expandiu para outros logradouros, como a Praça do Marquês, no bairro Marquês aos sábados, a Prainha às sextasfeiras em frente às barracas, na Avenida Maranhão, a Praça 16 de Agosto, no bairro São Cristóvão às quintas-feiras, e a Praça do Parque Piauí, às quartas-feiras no bairro de mesmo nome. O objetivo desse projeto cultural, segundo informaçóes da Coordenação de Feiras Populares de Arte da Secretaria de Cultura, Desportos e Turismo, publicada em matéria do jornal $O$ Dia, era de "[...] manter viva a arte popular em todas as suas manifestações; facilitar a comercialização de trabalhos artesanais, bem como de bebidas e comidas típicas e, acima de tudo, proporcionar lazer sadio para a nossa comunidade" (Parque..., 1984, p. 5).

A Feira Popular de Arte da Praça Saraiva era frequentada por crianças, jovens e adultos, principalmente após a missa na Igreja das Dores. Após o momento sagrado da missa, os teresinenses se destinavam à vida profana da feira, para assistir as variadas atraçóes culturais que se apresentavam num palco e para consumir as comidas e bebidas típicas da região nordeste, como mingau de milho e a cajuína piauiense. Sobre esse consumo de comidas típicas, o professor e diretor de teatro Chico Filho (2012) relatou em entrevista para este trabalho que era algo folclorizado. Ou seja, segundo ele, essa culinária não era comum na mesa do teresinense, restringindo-se apenas a determinados períodos e certos eventos, como as festas juninas e a própria feira da Praça Saraiva. Até mesmo o consumo de cajuína, que é um dos símbolos do Piauí, seria algo raro nos bares e restaurantes de Teresina.

Outro artista que frequentou e se apresentou nessa feira cultural foi o maestro Aurélio Melo. Em sua narrativa oral, ele destacou o fato de que o evento reunia quase toda a cidade e era palco para variadas manifestaçóes culturais, como música, dança e teatro. E ainda haveria as programaçóes temáticas que se aliavam às festividades regionais e nacionais, como era o caso dos festejos juninos e do carnaval.

[...] A Praça Saraiva foi o palco durante uns dez anos mais ou menos. Da

2 Esse projeto cultural foi criado no início dos anos 1980 e se estendeu por toda essa década, no governo estadual de Lucídio Portella Nunes (1979-1983), do Partido Democrático Social (PDS), por meio da Secretária de Cultura, gestada na época por Wilson de Andrade Brandão (Santos; Kruel, 2009). 
Feirinha de Arte né. Feirinha de Arte. Engraçado você tá me lembrando aí e serve até para registrar e ilustrar né. Mas como eu falei das praças, eu ia até esquecendo que durante uns dez anos a cidade quase toda ia pra lá. E lá acontecia tudo! Acontecia show de todos os artistas, manifestaçóes de cultura, dança, teatro e tudo. Quando era São João, era São João. Quando era carnaval, era carnaval. Mas toda semana tinha esse movimento lá. Além da bebida, da comida e tudo, tinha essas atraçóes culturais. (Aurélio Melo, 2015).

Antes de realizarmos a entrevista com o maestro Aurélio Melo e com os demais contadores de histórias, nos preparamos teoricamente seguindo a metodologia da História Oral. Entre os vários estudos a que tivemos acesso, nos fundamentamos nas "Sugestôes para um jovem pesquisador" da psicóloga Ecléa Bosi (2003). Essa pesquisadora da memória social sugere que antes da entrevista ou até mesmo antes do primeiro encontro com o narrador oral, se faz mister que o entrevistador recolha o máximo possível de informaçóes sobre o assunto que será pauta, para formular questóes que estimulem respostas. Assim fizemos. Pesquisamos previamente informaçóes sobre os espaços culturais de Teresina em livros, artigos e jornais. Essas informaçôes prévias nos ajudaram a estimular as lembranças dos nossos contadores de histórias, resultando em uma gratidão mútua. Isto é, entrevistado e entrevistador participaram de uma aventura comum durante o ato mnemônico. Nesse momento, o ouvinte fica grato pelo que aprendeu e, o narrador se sente importante pelo fato de narrar um passado que se mostra relevante para um registro histórico.

Durante a narrativa oral de Aurélio Melo (2015) apontamos alguns espaços culturais, como o Teatro de Arena e a Feira Popular de Arte da Praça Saraiva, no intuito de estimular suas lembranças. Nossas intervençóes surtiram um efeito positivo para a pesquisa, uma vez que contribuímos para enriquecer a construção daquele relato oral. Ao citarmos a Feira Popular de Arte da Praça Saraiva, o entrevistado logo percebeu a intencionalidade de nossa ação e teve consciência da importância daquele registro memorialístico, colocando-se como partícipe e protagonista dessa fase da produção historiográfica. "Engraçado você tá me lembrando aí e serve até para registrar e ilustrar né" (Aurélio Melo, 2015). Esse reconhecimento do ato mnemônico, com a intencionalidade do registro memorialístico foi perceptível em outro trecho de sua narrativa, quando citamos o Teatro de Arena. "Ah! O Teatro de Arena também! Exatamente! Lembrou bem. O Teatro de Arena, fizemos shows ali, e muitos. [...] Aconteciam festivais lá" (Aurélio Melo, 2015). Estimulamos as lembranças de Aurélio Melo, pois compartilhamos das ideias de Alessandro Portelli quando afirma que 
[...] ao contrário da maioria dos documentos históricos, as fontes orais não são encontradas, mas cocriadas pelo historiador. Elas não existiriam sob a forma em que existem sem a presença, o estímulo e o papel ativo do historiador na entrevista feita em campo. (Portelli, 2016, p. 10, grifos no original).

As fontes orais são geradas por meio da interação entre entrevistador e entrevistado, durante o momento da entrevista. Assim, o historiador estimula a memória do entrevistado e pode ser estimulado, a fazer novas perguntas (indo além do roteiro), com base nas respostas orais, gestuais e até silenciosas dos narradores.

O Teatro de Arena Santana e Silva, localizado no interior da Praça Marechal Deodoro da Fonseca (conhecida como Praça da Bandeira), foi outro espaço cultural que reuniu artistas e um público ávido por produçôes culturais gratuitas. Esse teatro foi inaugurado em 5 de novembro de 1965 com o nome de Conjunto Cultural Hélio Correia Lima e, desde entáo, foi palco de produçóes artísticas locais na área de teatro, dança e música. Nos anos 1980 e 1990 sediou eventos que repercutiam em toda cidade, como o "Festival de Violeiros do Norte e Nordeste", o festival de música "Chapadão" e o "Projeto Enquanto o Ônibus Não Vem".

Esses eventos culturais, realizados no Teatro de Arena, ocorreram em um período onde o contexto político municipal e estadual ainda era movido pelas tradicionais agremiaçóes partidárias, como o Partido Democrático Social (PDS), o Partido do Movimento Democrático Brasileiro (PMDB) e o Partido da Frente Liberal (PFL). Essas açóes se assemelhavam, em meio a diferentes governos municipais e estaduais, no intuito de valorizar a cultura local/regional e promover o surgimento de novos talentos artísticos na música e no teatro (Santos; Kruel, 2009).

O "Projeto Enquanto o Ônibus Não Vem” tinha a característica de atrair não apenas um público que já tinha costume de consumir produçôes artísticas, mas também pessoas que iriam assistir pela primeira vez a uma apresentação de teatro, de dança ou de música com composiçóes autorais locais. Isto ocorria porque o principal ponto de ônibus da cidade ficava localizado na Rua Coelho Rodrigues, ao lado da Praça da Bandeira e bem próximo do Teatro de Arena. Portanto, o nome do projeto sintetizava um de seus objetivos que era justamente atrair pessoas que estavam esperando o ônibus e, enquanto ele não vinha (e demorava muito, às vezes até quarenta minutos ou mais!), poderiam assistir gratuitamente uma apresentação artística (nas sextas-feiras a partir das $18 \mathrm{~h}$ ).

A uma distância de seis quadras do Teatro de Arena, ficava localizado o Ginásio Poliesportivo Dirceu Mendes Arcoverde, mais conhecido pela população teresinense como "Verdáo". Além de sediar vários eventos esportivos, esse espaço 
se configurou como uma das principais casas de shows de Teresina. Nesse espaço se reuniam artistas locais e nacionais como Roberto Carlos, Caetano Veloso, Alceu Valença, Roupa Nova, Kid Abelha e RPM. Esses shows musicais no Verdão atraiam milhares de jovens, que sociabilizavam dentro e fora desse espaço. A "festa" começava do lado de fora quando multidóes faziam fila para entrar. Nesse ínterim, os amigos conversavam sobre a expectativa em relação àquele show e outros já assistidos, degustavam algumas comidas e bebidas vendidas por ambulantes e chegavam a passar por algumas aventuras para poder entrar no ginásio. Foi o caso do músico André Luiz Oliveira Eugênio de Souza, que, mesmo com ingresso comprado, teve dificuldades de entrar no Verdão para assistir a um show da banda RPM, devido a uma multidão que já estava dentro e de outra que queria entrar. Em entrevista para o historiador Hermano Carvalho Medeiros, esse músico relatou a experiência dessa aventura, a sua análise técnica da acústica do espaço, a forte interaçáo que geralmente existia entre o público e alguns artistas que por lá se apresentaram.

Uma coisa que faz muita falta é o Verdão [...] que tinha uma acústica maravilhosa. Passavam todos os shows importantes por aqui. Eu lembro que eu fui ver o RPM no auge mesmo, eu e minha namorada a gente não conseguia [...] tinha aquela corrente de seguranças [...] era gente demais. A gente com ingressos na mão. Aí ele disse: "olha, eu vou levantar o braço um segundo, quem passar, passou!" ele olhando pra mim [...] "se você não passar fica. Ela vai só”. O cara levantou... a gente pulou pro outro lado! Lá dentro se você tirasse o pé, não tinha onde colocar... tinha que colar em cima de outro pé. Quer dizer, todos os shows [...] Eu lembro que o Alceu também, da época do Cavalo de Pau. Teve uma hora que teve um problema com a guitarra do Paulo Rafael. Ele começou simplesmente o Verdão cheio, lotado e ele começou a brincar, fazer Repente enquanto se resolvia o problema [...] agradeceu todo mundo pela compreensão e aplaudiram quase 15 minutos o cara. Era cheio em cima e em baixo. (Souza, apud Medeiros, 2014, p. 170).

Outro espaço musical da cidade de Teresina foi o Auditório Herbert Parentes Fortes, onde muitos músicos teresinenses se apresentavam desde os anos 1970. Esse auditório ficava localizado na Avenida Miguel Rosa, próximo ao cruzamento com a Avenida Frei Serafim. Apesar de pequeno, pois comportava um público de pouco mais de 150 pessoas, ele funcionou como uma vitrine para muitos músicos que estavam em início de carreira, como Geraldo Brito e Edvaldo Nascimento. Estes músicos relataram, em entrevista, que participaram de um movimento chamado "Show Piau" em 1975, onde os artistas poderiam mostrar 
suas músicas autorais e havia espaço para literatura e teatro. Edvaldo Nascimento explicou em seu relato oral que o "Show Piau",

[...] Era um movimento musical que reunia não só música, no [Auditório] Herbert Parentes [Fortes]. Ainda hoje tem o auditório lá. Foi ali que começou um grande movimento de literatura, de música, de performance de teatro. O Show Piau! [...] E lá nesse espaço começou a fomentar a coisa da composição própria. Que antigamente as bandas daqui só faziam cover, de Renato e seus Blue Caps. Mais bandas de baile né. Quem quebrou essa coisa de compor, fazer composição foi o Geraldo Brito, eu, Cruz Neto, Naeno, o Aurélio Melo. (Edvaldo Nascimento, 2015).

Além da música, como destacou Edvaldo Nascimento, o Auditório Herbert Parentes Fortes foi palco de exibições cinematográficas, de lançamentos de livros, de apresentaçóes de teatro e de dança, de saraus, bem como dos tradicionais debates, palestras e outros eventos acadêmicos.

\section{Os bares: espaços culturais alternativos}

A cidade de Teresina possuía outros espaços que à primeira vista não poderiam se configurar em si como culturais, ${ }^{3}$ mas que eventualmente eram frequentados por artistas que faziam seus shows particulares e independentes. Era o caso dos bares. Esses espaços privados agitavam as cenas culturais da cidade. De acordo com nossos entrevistados, a boemia artística teresinense se fazia presente em espaços como o Sachas Bar, o Arte Bar, o Bar do Cuspe, o Bar do Toinho, o Café das Seis, o Bar da Sulica, o Bar Avenida, o Chaparral, o Raízes, a Churrascaria Beira Rio e o restaurante De Comer. Entre esses bares, havia outros que além da espontânea frequentação de artistas, ofereciam uma programação artística mais sistematizada aos seus clientes. Essa programação artística foi configurando esses bares como verdadeiros espaços culturais. Foi o caso do Bar Havana, do Pacatuba, do Encena, do Artes e Trastes, do Barbárie, do Green Bar, do Zeus, do Elis Regina e do bar Nós e Elis. Não faremos aqui uma discussáo de todos esses bares, mas apenas daqueles que foram mais significativos para nossos contadores de histórias, como o Bar do Cuspe, o Sachas Bar, o Green Bar, o Zeus, o bar Elis Regina e o bar Nós e Elis. Esses espaços privados constituíam-se como uma alternativa aos

3 Esses espaços não ofereciam uma programação artística para seus frequentadores ou não havia uma sistematização de eventos culturais, bem como era apenas eventual a presença de artistas. 
espaços públicos que ofereciam atividades culturais e eram gerenciados pelo poder público municipal e estadual.

O Bar do Cuspe ficava localizado na Rua 13 de Maio em frente à Praça Pedro II. Esse bar funcionou durante os anos 1970 e 1980 (fechando suas portas em 1983), sendo constituído fisicamente por um fino corredor com aproximadamente $35 \mathrm{~m}$ de comprimento, com 3,5 m de largura, um balcáo comprido e cadeiras e mesas de madeira bastante desgastadas (Sampaio, 1994).

$\mathrm{O}$ ator e dramaturgo Wellington da Silva Sampaio escreveu uma crônica sobre esse bar, intitulada "Bar do Cuspe", sendo classificado em $3^{\circ}$ lugar no I Concurso de Crônicas A. Tito Filho em 1993. Nesse texto literário, ele aponta a constante movimentação do bar que, apesar de pequeno e bem simples, atraia intelectuais e artistas de renome nacional, como os cantores Luís Melodia e Alceu Valença, e local, como o artista plástico Arnaldo Albuquerque, o ator e dramaturgo Afonso Lima, os atores Santana e Silva e Tarcísio Prado e o maestro Reginaldo Carvalho. "Dizem até que o nome Bar do Cuspe foi batizado pelo ilustre maestro Reginaldo Carvalho. Acredito que este nome veio em função dos muitos que lá bebiam e tinham como hábito cuspir no chão" (Sampaio, 1994, p. 135).

O proprietário do bar era conhecido como Seu Expedito e tinha a característica de atender bem todos os frequentadores, deixando-os à vontade. $\mathrm{O}$ carisma do proprietário, somado à tranquilidade do ambiente e à localização privilegiada, atraíram muitos boêmios àquela casa noturna, que não tinha hora para fechar. "Lá se brigava, se namorava, se discutia da música clássica ao Peru Rodou, da Maria da Inglaterra, bem como do teatro Brechiniano ao Grupo Beleza. Nada passava despercebido dos ávidos frequentadores do BDC” (Sampaio, 1994, p. 135).

Um desses ávidos frequentadores do Bar do Cuspe foi o ator e cantor Moisés Chaves. Ao ser questionado por nós, durante a concessão de entrevista para este trabalho, sobre os espaços de sociabilidade de Teresina nos anos 1980, frequentados especialmente por artistas, ele foi enfático ao responder que "Tinha uma coisa boa que era ainda o 'quebra bunda' do Theatro 4 de Setembro e o Arte Bar, que fica ao lado do Bar do Cuspe. Então, assim, na década de 80 eram os pontos que os artistas frequentavam [...]" (Moisés Chaves, 2012).

O Bar do Cuspe fechou suas portas em 1983 e, em seu lugar, passou a funcionar uma lanchonete. Atualmente, o espaço físico desse antigo bar continua resistindo ao tempo, com a nova funcionalidade. Para o cronista Wellington Sampaio, essa resistência não é apenas física, material, mas também sensível, imaginária. Isto porque os fantasmas dessa antiga casa noturna ainda estariam ali tomando vinho gelado em doses ou copo cheio, pedindo fiado ao Seu Expedito.

Ao entrarmos no mesmo local [depois de fechado por dez anos], ainda sentimos a vibração das acirradas discussóes e a presença dos espíritos dos 
frequentadores que já partiram deste mundo, mas que ainda hoje caminham pelo seu corredor. (Sampaio, 1994, p. 136).

O Sachas Bar ficava localizado na Avenida José dos Santos e Silva, próximo ao atual prédio da Agência de Desenvolvimento Habitacional do Estado do Piauí (ADH), tendo funcionado do final dos anos 1970 ao início da década de 1980. Não sabemos o motivo da nomeação do bar como Sachas. Segundo a narrativa oral de Afonso Lima (2015), o proprietário desse bar (que ele náo recordou o nome) era chamado por alguns frequentadores como Sachas. Porém, esse vocativo não se referia ao seu nome de registro civil, mas, pois, há um costume nas pequenas e médias cidades brasileiras de se personificar os bares na figura do seu proprietário, até mesmo quando eles possuem um nome diferente. Assim, muitos bares de Teresina ficaram conhecidos como "Bar do Toninho", "Bar da Sulica", "Bar do João", "Bar do Elias”, entre outros.

Ressaltamos que em nossa pesquisa soubemos da existência de uma casa noturna no Rio de Janeiro que se chamava "Sacha's". Esse bar/boate carioca ficava localizado no Leme - um bairro nobre do Rio de Janeiro - e durou cerca de dez anos (1954-1964), com a administração dos sócios Carlos Machado e Sacha Rubim. Sacha Rubim era um pianista de muito sucesso na alta sociedade e, devido à sua fama, aquela nova casa noturna recebeu seu nome, incluindo ainda o slogan "Seven to seven". O slogan não era à toa, aquele espaço boêmio era o primeiro a abrir e o último a fechar, pelo menos até antes do golpe de 1964, quando as casas noturnas passaram a fechar às $2 \mathrm{~h}$ da madrugada.

Em nosso estudo, não soubemos se o Sachas teresinense homenageava aquele bar carioca. Contudo, percebemos algumas aproximaçóes e distanciamentos que podem ser melhor discutidos em um estudo histórico específico. As diferenças estão no período de funcionamento, pois o bar teresinense teria durado apenas alguns anos entre o final dos anos 1970 e o início dos anos 1980, já o bar carioca durou cerca de dez anos, de 1954 a 1964; na estrutura física, o bar teresinense era bem simples, enquanto o carioca era bem sofisticado, com muito requinte na decoração; e na clientela, o bar teresinense era frequentado geralmente por jovens artistas (e não artistas) com poucos recursos financeiros, já o carioca era frequentado por um público de meia idade da alta sociedade política e econômica. As semelhanças estavam no nome, já que ambos foram nomeados como Sachas, com uma pequena variação na grafia; no horário de funcionamento, ambos abriam cedo e só fechavam na manhã do dia seguinte; no comportamento excêntrico e transgressor de seus frequentadores, pois no bar teresinense alguns casais homoafetivos namoravam livremente e outras pessoas consumiam drogas, 
o que era um escândalo para a época, já o carioca tinha um telefone instalado no banheiro feminino que, entre outras utilidades, permitia a marcação de encontros extraconjugais na área do saláo do bar/boate e, também havia o caso de alguns clientes, como o casal Ricardo e Olívia Fasanello, que chegavam a levar animais selvagens para dentro daquela casa noturna. ${ }^{4}$

No Sachas Bar teresinense não havia apresentações artísticas, mas, segundo o relato oral de Ací Campelo (2015), era o local onde muitos artistas se encontravam, principalmente atores e atrizes. Nesse bar, o referido dramaturgo, apesar de ser tímido e/ou contido, participava de rodas de amigos que bebiam compulsoriamente e discutiam todos os temas, de forma bastante debochada e em voz alta, chamando a atenção de outras mesas. O Sachas era o bar da descontração quase sem limites, onde principalmente atores e atrizes faziam "shows particulares" fora do palco. Nesses "shows particulares" os artistas cantavam, faziam performances teatrais e até faziam cartuns em guardanapos de papel, que eram colados nas paredes. A atriz Lari Sales foi uma assídua frequentadora desse bar e, em uma narrativa oral bastante eufórica, ela relatou que

[...] O [bar] Nós e Elis era esse mais global e o Sachas [bar] não, era mais teatral. Esses três grupos de teatro se encontravam lá [Grupo TESTE, de Tarcísio Prado, GRUTEPE, de Afonso Lima e Grupo Raízes, de Ací Campelo]. [...] A gente fazia mais era cantar né [nas mesas do bar]. A gente ia pra bagaceira mesmo. Era pra beber, pra namorar, pra se conhecer, pra se encontrar... [...] A gente não tinha muito essa preocupação, que a gente tem hoje quando a gente vai num lugar e pensa logo se vai conseguir trabalhar nele. Porque hoje os artistas têm contas pra pagar e não sei o quê. A gente não estava preocupado com isso. A gente estava preocupado em se divertir. Se tivesse espaço pra se apresentar, um dia a agente se apresentava, mas não era o nosso foco e tal. Mas mesmo assim, a gente apresentava lá [faziam performances teatrais improvisadas]. (Lari Sales, 2015).

$\mathrm{Na}$ história contada por Lari Sales, não apreendemos apenas as informaçóes sobre o Sachas Bar e os outros espaços culturais da cidade de Teresina. O momento da entrevista com essa atriz nos permitiu também ter acesso a um conhecimento subjetivo sobre o cotidiano teresinense nos anos 1980 e 1990, que se traduziu, inicialmente, nas informaçóes expressadas por sua voz. Isto ocorreu porque segundo as reflexôes de Sônia Maria de Freitas,

$\mathrm{Na}$ reconstrução do passado, a linguagem auditiva, que se baseia essencialmente no uso da voz, exercerá um papel fundamental. Pois é como 
discurso que a memória evidencia todo um sistema de símbolos e convençôes produzidos e utilizados socialmente. Além disso, a voz é um elemento em si mesmo. Suas variações dão sentido ao texto transmitido, transformam-no, dando-lhe, muitas vezes, um significado além do que foi meramente dito. (Freitas, 2002, p. 47-48).

Faz-se mister ressaltar que esse significado do relato oral, que vai além do que foi dito, não se dá apenas pelas variaçóes do tom de voz do narrador, mas também pela variação do ritmo da narrativa (ora acelerada, ora mais lenta), pelos gestos corporais, pelo olhar e pelos silêncios e esquecimentos. Todas essas variaçóes que geralmente acompanham o ato mnemônico se fizeram presentes durante a contação de histórias de Lari Sales e nos fizeram entender que "a tonalidade e as ênfases do discurso oral carregam a história e a identidade dos falantes, e transmitem significados que vão bem além da intensão consciente destes" (Portelli, 2016, p. 21); bem como nos deram pistas de como se constituía o passado de Teresina no recorte temporal de nossa pesquisa.

A nostalgia da narrativa oral de Lari Sales foi reforçada por um brilho no olhar e por um constante movimentar de braços. Esses elementos que acompanhavam o seu ato mnemônico passavam a ideia de que a entrevistada queria restaurar o seu passado boêmio onde ela e seus amigos tinham muito prazer em curtir os espaços culturais da cidade (representados no Sachas Bar, naquele momento da entrevista), onde a única regra era ser feliz, onde a única preocupação era se divertir.

Faz-se oportuno frisar que os exercícios de memória não constituem um ato de restauração do passado, mas uma reconstrução deste tempo que se realiza no presente. Fundamentado nesse pensamento, podemos considerar que Lari Sales náo restaurou o seu passado (com seu relato oral), mas o reconstruiu com base no seu presente, onde ela aproveitou para criticar a sociedade atual, onde a conjuntura socioeconômica não estaria permitindo que o jovem (artista) circulasse e se divertisse livremente, sem preocupaçóes, pela cidade (Bosi, 2003).

Outro assíduo frequentador do Sachas Bar foi o dramaturgo José Afonso de Araújo Lima, mais conhecido como Afonso Lima, no meio artístico. Um dos motivos dessa frequência é o fato de que o bar ficava localizado bem próximo de sua casa, no centro da cidade. Esse dramaturgo, em entrevista, lembrou da pequena estrutura física dessa casa noturna, da presença de muitos artistas que movimentavam a cidade com suas produçóes culturais e das atividades pitorescas que por lá se realizavam.

Sachas Bar era quase em frente à minha casa. Era todo dia também, porque lá também era outro point [...] era um barzinho assim, uma coisinha estreita, quase na calçada, espremido. [...] Lá era tudo, Albert Piauí, fazen- 
do aquelas coisas que ele faz [...] Cartuns, não sei o que... Tinha na parede tudo isso, tinha... acontecia também muita coisa por lá, nesse bar. Todo mundo estava nesse bar. Todo mundo da época cultural, dessa época efervescente estava lá. Albert Piauí, pessoal Ací Campelo, Assaí.... Campelo! E muitas coisas aconteceram... [...] E era lotado. Ali era o bar da cachaça, lotado, lotado, todo mundo saía bebo. (Afonso Lima, 2015).

O Sachas Bar, segundo o relato oral de Afonso Lima, era o espaço da liberdade em pleno regime militar brasileiro. Lá os casais homoafetivos namoravam tranquilamente (trocavam beijos e carícias), os escritores da chamada "Geração Mimeógrafo" 4 distribuíam seus rudimentares panfletos com textos líricos (como era o caso do poeta Wiliam Melo Soares, que vivia sua poesia, fazendo flaneries pela cidade) ou de protesto e consumia-se drogas ilícitas abertamente, sem nenhum receio.

No entanto, essas "açóes livres" não eram fruto apenas de espontaneidades, mas também se configuravam intencionalmente como atos políticos contra a moralidade vigente, difundida tanto pelo Estado quanto pela sociedade civil organizada em suas instituiçóes familiares e religiosas. Portanto, a maior parte da sociedade e o Estado militarizado eram contra essas "açóes livres" realizadas no Sachas Bar ou em qualquer outro espaço da cidade, o que resultava numa constante presença da polícia para cercear esses atos transgressores. Na narrativa oral de Afonso Lima, ele também destacou esse comportamento livre no Sachas Bar, que às vezes continuava em ruas e praças na circunvizinhança e eventualmente resultava em prisóes.

Ali era o bar da cachaça, [onde muitos frequentadores] Eram presos. Eu mesmo fui tirar gente da cadeia ali perto, saía, dobrava e eles iam pra porrada... [O motivo das prisóes, era] Por tudo, era perseguição da polícia [...] Perseguição, tinha muito maconha, muito cocaína, essas coisa toda, enrolavam abertamente. E artistas. Era maioria tudo artista que vão lá, grupo de teatro, de música, escritores da geração chamada mimeógrafo, [...] Nenhum desses grandes [escritores] piauienses passavam por lá não. [...] Aconteceu uma coisa horrível, de um cara legal, um rapaz lá. Me esqueci o nome. Muito bonito. Foi até assassinado. Não lá, mas saindo de

4 Para maiores informaçóes sobre a "Geração Mimeógrafo" confira o texto monográfico "Pelas margens: Geração Mimeógrafo no Piauí na década de 1970” de Gislane Cristiane Machado Tôrres de 2007. No terceiro capítulo dessa monografia, a autora faz uma análise das visôes da cidade de Teresina e de sua cotidianidade nas produçóes literárias "centrais" e (principalmente) marginais que retratavam o ideal progressista (defendido e combatido) na década de 1970. 
lá. Assassinado por lá, nas facadas, pro rumo da Piçarra. Uma coisa triste isso aí, que abalou um pouco lá. E essas histórias de... (risos) da polícia, sempre perseguindo, sempre perseguindo. [...] [Lá, os frequentadores] faziam de tudo! Tudo! Essas coisas era muito livre, entendeu? Quem queria as coisas queriam e faziam, e faziam e não tinham vergonha. [...] [Sobre relacionamentos entre homossexuais no bar] Beijos tinha, não tinha era sexo mesmo. Mas aí saía e ia transar em qualquer lugar. Mas beijar na boca, se abraçar e... tinha tudo isso. Normal. Era aberto, mulher com mulher, homem com homem, tinha demais, né! [...] Em plena ditadura! [...] [o artista plástico] Arnaldo Albuquerque fez um escândalo. Ele pegou Robinho ali na praça. Estava tendo um grande movimento, um festival de teatro, alguma coisa... E se beijavam na boca era no meio da rua. Ali na Praça Pedro II. Ali na Praça João Luiz Ferreira. Estava tudo se beijando. (Afonso Lima, 2015, grifo nosso).

A narrativa oral acima citada pode ser entendida, seguindo a acepção de Verena Alberti, como um "resíduo de ação", pois “[...] é, ao mesmo tempo, um relato de açóes passadas e um resíduo de açóes desencadeadas na própria entrevista" (2004, p. 34). A entrevista com Afonso Lima, assim como as outras que realizamos para este trabalho, documentou uma ação interativa entre narrador e ouvinte e interpretou o passado de forma ativa - nesse caso específico, ao ir além da informação, analisando os fatos ocorridos.

Outro bar que teve a presença constante de artistas, mas que, diferente do Sachas Bar, de fato se configurou como espaço cultural, foi o Green Bar. Ele ficava localizado na Rua das Orquídeas, próximo à Igreja de Nossa Senhora de Fátima, na zona leste de Teresina, tendo funcionado durante o ano de 1990. Esse bar foi administrado pelo músico Edvaldo Nascimento e por sua esposa, a professora e literata Edna Nascimento. Apesar de ter durado apenas um ano, o Green Bar teve uma intensa programação artística que incluía apresentaçóes de música, teatro e humor. Entre os músicos que por lá se apresentaram estavam Chagas Vale, Gabi e o próprio Edvaldo Nascimento com seus shows de rock. As artes cênicas tinham espaço por meio de performances teatrais realizadas por atores como Amauri Jucá e Dirceu Andrade, além de alguns espetáculos que não exigiam uma grande estrutura de palco, como o premiado monólogo "Apareceu a Margarida" interpretado por Lari Sales. Os shows de humor com João Claudio eram uma das atraçóes que lotavam aquela casa noturna. Esse bar fechou as portas devido a problemas financeiros e administrativos, como aumento do preço do aluguel e questóes trabalhistas envolvendo os funcionários (Edna Nascimento, 2015).

Um bar (cultural) fecha as portas, outro as abre. Esse foi um dos pensamentos que levou outro casal de artistas a abrirem um novo espaço cultural em 
Teresina, no ano seguinte ao fechamento do Green Bar. O músico Geraldo Brito, em parceria com sua esposa, a atriz Vera Leite, alugaram uma casa na Rua Senador Teodoro Pacheco (a mesma rua que passa em frente ao Theatro 4 de Setembro), no centro da cidade, que serviria ao mesmo tempo como local de trabalho e residência para o casal. O casarão com seus vários cômodos e amplo quintal foi reformado para abrigar o Espaço Cultural Zeus ou simplesmente Zeus, como ficou mais conhecido o lugar, que funcionou no período de 1991 a 1995. Segundo o relato oral de Vera Leite, o nome do bar foi escolhido não para fazer uma referência direta ao deus da mitologia grega, mas ao título de uma das músicas de maior sucesso de Geraldo Brito na época.

[...] É porque era o nome de uma música do Geraldo, "Zeus”, a música que naquela época... Hoje já deve ter outros sucessos maiores. Mas na época era a música de maior sucesso, era "Zeus" que foi gravada por várias pessoas. Então, nós colocamos Zeus, que também tinha um duplo sentido né é o deus né. [...] A letra sim, a letra da música, a letra da música né era uma referência ao Zeus grego. E a casa [o bar Zeus] era referência ao deus da cidade (riso) porque realmente era a casa onde todos iam. (Vera Leite, 2015).

O bar Zeus possuía dois palcos, um na parte interna e outro na área externa, onde se apresentavam os músicos locais com repertório autoral e fazendo covers de cantores consagrados, como Caetano Veloso, Chico Buarque e Roberto Carlos. Essas apresentações eram noticiadas na agenda cultural do jornal O Dia, como podemos observar nas publicaçóes dos dias 27 de janeiro e 29 de abril de 1995:

Geraldo Brito, Rubeni Miranda e Edgar Lippo, [músicos piauienses] tocam chorinho, toda quinta-feira, às 22h00, no Espaço Cultural Zeus. (Shows, 1995, p. 18).

Música ao vivo toda quarta-feira no Espaço Cultural Zeus, relembrando grandes sucessos de Roberto Carlos. Quinta-feira tem chorinho. Rua Senador Teodoro Pacheco, no 727/Centro. (Shows, 1995, p. 20).

Nesse espaço também havia apresentações de performances teatrais, sendo que um dos grupos que fez muito sucesso nessa programaçáo cênica foi a Companhia de Homens, com suas esquetes críticas, criativas e cheias de humor. Essa casa noturna também funcionou como um grande aglutinador de artistas, 
devido sobretudo ao seu proprietário, que tinha um vasto leque de laços de amizades com pessoas da área artística e, também, porque o bar ficava bem próximo ao Theatro 4 de Setembro. Ou seja, geralmente, depois das apresentaçôes, tanto de artistas locais como também os de expressão nacional, nesse teatro, os artistas iam confraternizar naquele bar temático, pois sabiam que iriam encontrar pessoas que também produziam arte e/ou que a apreciavam (Vera Leite, 2015).

Seguindo essa linha de bares administrados por artistas, a boemia teresinense contou ainda com outro espaço que em "tudo" respirava arte. Esse foi o bar Elis Regina, administrado pelo ator e produtor cultural João Batista Sousa Vasconcelos. A história desse espaço cultural começou quando o então presidente da União Brasileira de Escritores do Piauí (UBE-PI), Kenard Kruel, convidou João Vasconcelos para ficar responsável pela parte do bar. No prédio da UBE-PI, localizado na Rua David Caldas, esquina com a Rua Félix Pacheco e próximo da Central de Artesanato Mestre Dezinho, onde funcionava a Casa da Poesia, a UBE Mirim e um espaço para um café, que logo foi transformado em bar cultural devido a experiência de João Vasconcelos na administração de outras casas de divertimento (Santos; Kruel, 2009). Esse ator/produtor cultural já havia administrado, juntamente com sua esposa Lourdes Vasconcelos, o Café das Seis (na Rua São Pedro com a Rua 24 de Janeiro), o Encena (uma sociedade com os atores Wilson Costa e Lorena Campelo, localizado na esquina das avenidas Maranhão e Campo Sales) e, depois do Elis Regina, ainda esteve à frente do Arte de Comer (na Rua Treze de Maio, ao lado do Theatro 4 de Setembro), de um espaço na parte superior do prédio da $\mathrm{ADH}$, onde vendia comidas, bebidas e levava atraçóes culturais e, atualmente, administra o bar do Clube dos Diários (João Vasconcelos, 2015).

O bar Elis Regina funcionou por três anos (de 1996 a1998) no período em que o Theatro 4 de Setembro estava fechado para uma reforma. Tal fato contribuiu para que a maioria dos eventos e produçôes culturais se concentrasse nesse bar, como lançamento de livros, apresentaçóes de teatro, música e dança, festivais gastronômicos, realização de festas temáticas para o então público GLS (Gays, Lésbicas e Simpatizantes), realização de festivais de rock. O próprio João Vasconcelos, em entrevista, destacou a efervescente e variada programação cultural daquele bar onde, segundo ele, "acontecia de tudo":

[...] Então, lá pela localização foi o celeiro de grandes descobertas de novos nomes. Manutenção do produto cultural que já havia. [...] O que é que acontecia, o Projeto Boca da Noite [no espaço cultural Osório Júnior, anexo ao Theatro 4 de Setembro] ele acaba cedo, então quando acabava aqui, a moçada ia para o Elis Regina. A noite continuava e era mais longa ainda. Por lá nós tivemos a Cia de Homens que era uma referência naquele momento [...] Lá nós lançamos como atores o núcleo que era da [oficina 
de teatro] Procópio Ferreira, [...] Aconteciam diversos eventos paralelos, que tudo acontecia lá - lançamento de livros, festival de comidas até da Índia. Era um lugar pequeno, efervescente. [...] Lá nós criamos o Troféu Elis Regina que era o nome do bar. Onde a gente dava ele às pessoas que mais se destacaram por se apresentar no próprio espaço. [...] o bar Elis Regina [...] lá acontecia de tudo. De um evento da Maristela Gruber com Erisvaldo Borges, só cantando clássicos. Como acontecia a parte que eu poderia rotular como um bar gay, mas não é isso não. Lá foi um espaço cultural como o Nós e Elis. Lá nós tínhamos só homens com festas temáticas voltadas para o público GLS. [...] Até aos domingos o bar era aberto. Não tinha história de parar. Não. Era segunda, terça, quarta, quinta, sexta. Sempre tendo atividades. Eu lembro até que havia um movimento tão grande de rock, que foi lá que nasceu a [banda de rock] Narguilê, a banda Mano Crispim. As bandas vinham de vários estados para se apresentar no Elis Regina. E aí o bar Elis Regina entrou para uma revista nacional. Ele era referência. [...] Então lá, eu não citei, mas acontecia Festival de Performances [teatrais], [...] [tinha apresentações de] Espetáculos mesmo, como exemplo, a "Raimunda Pinto" que tinha uma estrutura. [o bar Elis Regina] Era pequeno, mas tinha palco. E às vezes tinha tanta gente nesse Elis Regina para ver por exemplo, a "Raimunda Pinto" que teve uma vez que o equipamento do Pizeca caiu umas três vezes. (risos) Era engraçado demais. [...] Embora o [bar] Nós e Elis tenha tido um tempo maior e ser um bar de proprietário de classe média. Ele tem uma história bem maior, por mais tempo. Mas o Elis Regina ficou na memória das pessoas por ser um bar atuante. Vinte e quatro horas, a gente saía de manhã e de manhã já voltava. [...] Foi um período que eu não tinha sossego não. [...] (João Vasconcelos, 2015).

No relato oral de João Vasconcelos, ele destaca, entre outras coisas, o fato de que havia uma grande movimentação de bandas de rock em sua casa noturna, da cidade de Teresina e de outros estados brasileiros. Ressalta ainda que o bar Elis Regina foi palco para o lançamento de algumas delas, como a Narguilê Hidromecânico e a Mano Crispim. Essa face roqueira dessa casa noturna também foi ressaltada pelos jornalistas Mara Vanessa e Diego Iglesias, em uma publicação do jornal $O$ Dia de 9 de outubro de 2010.

Um dos locais responsáveis pela união e expansão da cena [do rock] Metal em Teresina foi o [bar] Elis Regina, [...]. O ambiente era pequeno, apertado e aglomerado. Segundo Julieta Nogueira, uma das frequentadoras do Elis Regina, "o espaço era muito pequeno, do tamanho de um banheiro do 
Bueiro do Rock", brinca. O baterista das bandas Dark Season e Phantom of Death, Félix Briano, relembra que "o Elis era um casarão antigo. Pela arquitetura, deve ter sido construído na década de 1960. Mas o público não utilizava o ambiente interno da casa, e sim apenas o corredor lateral e o quintal. No corredor ficavam as mesas e no quintal um modesto palco de cerca de $50 \mathrm{~cm}$ de altura. Mas nesse diminuto palco foi onde eu subi pela primeira vez para me apresentar e onde muitas bandas fizeram sua estreia, com por exemplo o Into Morphin” [...]. (Vanessa; Iglesias, 2010).

$\mathrm{Na}$ narrativa oral de João Vasconcelos, podemos perceber que além de tecer comentários sobre o bar que ele administrou, ele fez referência a outra casa noturna, que também se configurou como espaço cultural em Teresina, o bar Nós e Elis. Este, por sua vez, funcionou num período anterior ao bar Elis Regina (de 1984 a 1995), sendo que ambos tinham dois aspectos principais em comum (apesar de João Vasconcelos ter frequentado pouco o bar Nós e Elis e não ter desenvolvido amizade com seu proprietário): eram espaços culturais que congregavam diferentes modalidades artísticas e seus nomes faziam uma homenagem à cantora Elis Regina.

Como se pode perceber, os principais espaços culturais de Teresina estavam localizados na região central da cidade. Ressaltamos que alguns jovens, especialmente aqueles ligados direta ou indiretamente às artes, após a socialização no centro desta urbe se destinavam à zona leste da capital para "completar a noite" no bar Nós e Elis.

O bar Nós e Elis era pequeno e simples em sua composição física e arquitetônica. Mas para seus frequentadores mais assíduos, era considerado grandioso e excepcional. $\mathrm{O}$ entusiasmo para com esse espaço apontava para um reflexo das múltiplas sensaçóes ali vividas, permeadas por sabores, cheiros, sons e visóes turvas ou clarificantes que por vezes levavam ao tatear, em um tropeço, em gentes e mesas, ou em um abraçar de corpos. Nessa casa de divertimentos noturnos, os convivas discutiam sobre todos os temas, em tons diplomáticos e/ou exaltados, a depender do assunto do momento ou do nível etílico em que se encontravam. O local acabou se tornando, em seus 11 anos de funcionamento, um ponto de encontro de amigos e de artistas que se reuniam no palco e na plateia, fato observável nas imagens a seguir. 

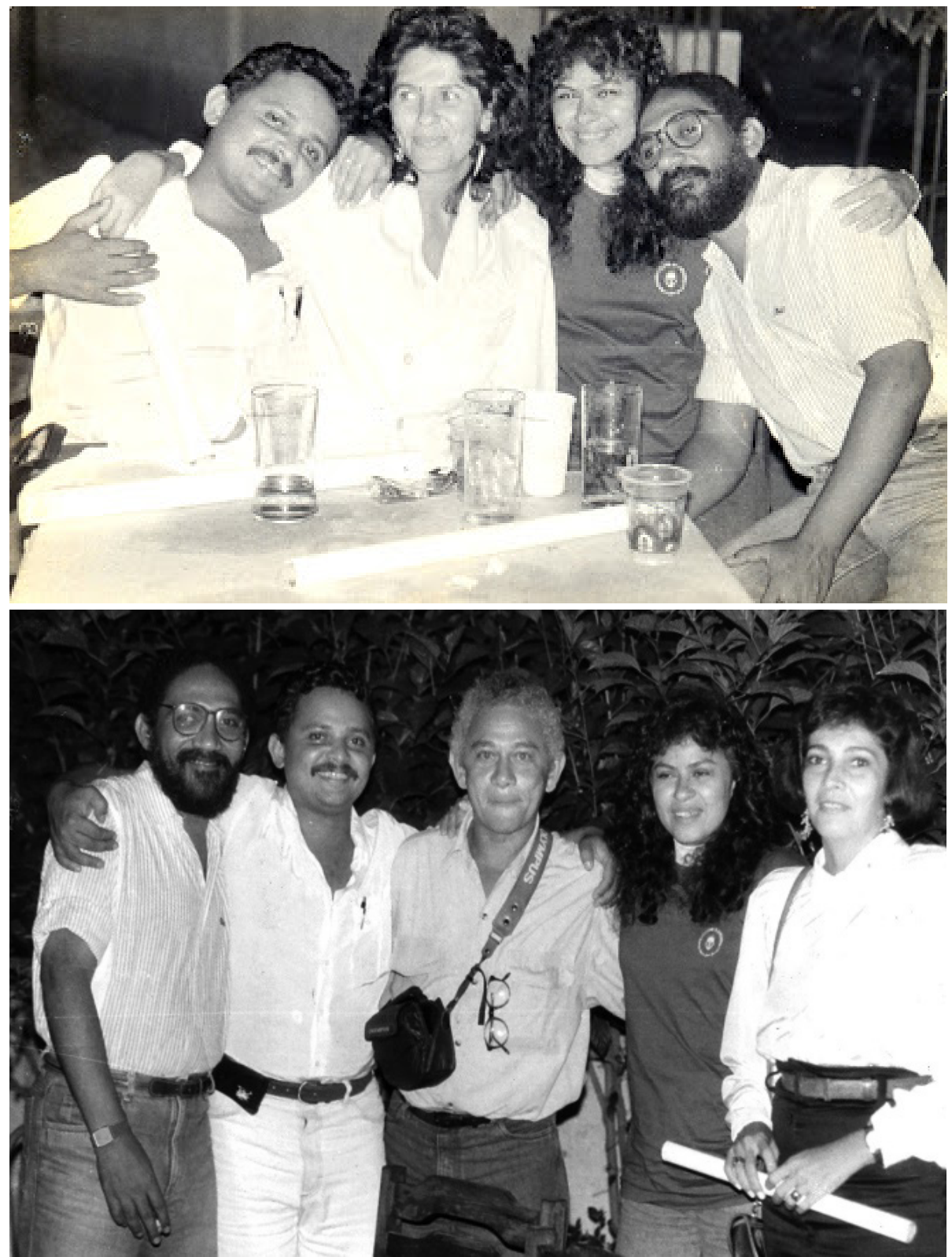

Figuras 1 e 2 - Encontro de amigos/artistas no bar Nós e Elis, em Teresina, em 1986. Na primeira foto estão o cartunista Paulo Moura, Lêda Guimarães, os cantores Fátima Lima e Rubens Lima. Na segunda foto estão o cantor Rubens Lima, o cartunista Paulo Moura, o pintor Nonato Oliveira, a cantora Fátima Lima e Mimita.

(Moura, 2008). 
Nessa casa noturna havia música ao vivo quase todos os dias e seus administradores procuravam valorizar os artistas locais. O Jornal da Manhã, em sua agenda cultural, publicou uma nota que registrou esse aspecto do referido espaço cultural: "O Nós e Elis foi reaberto e já está oferecendo aos visitantes bons shows com músicos variados da terra [...]" (Roteiro, 1988, p. 3). Entre os variados "músicos da terra" estavam Roraima, Maurício Mauller, Garibaldi Ramos, Geraldo Brito, Rubens Lima e Fátima Lima, como podemos observar nas imagens a seguir:

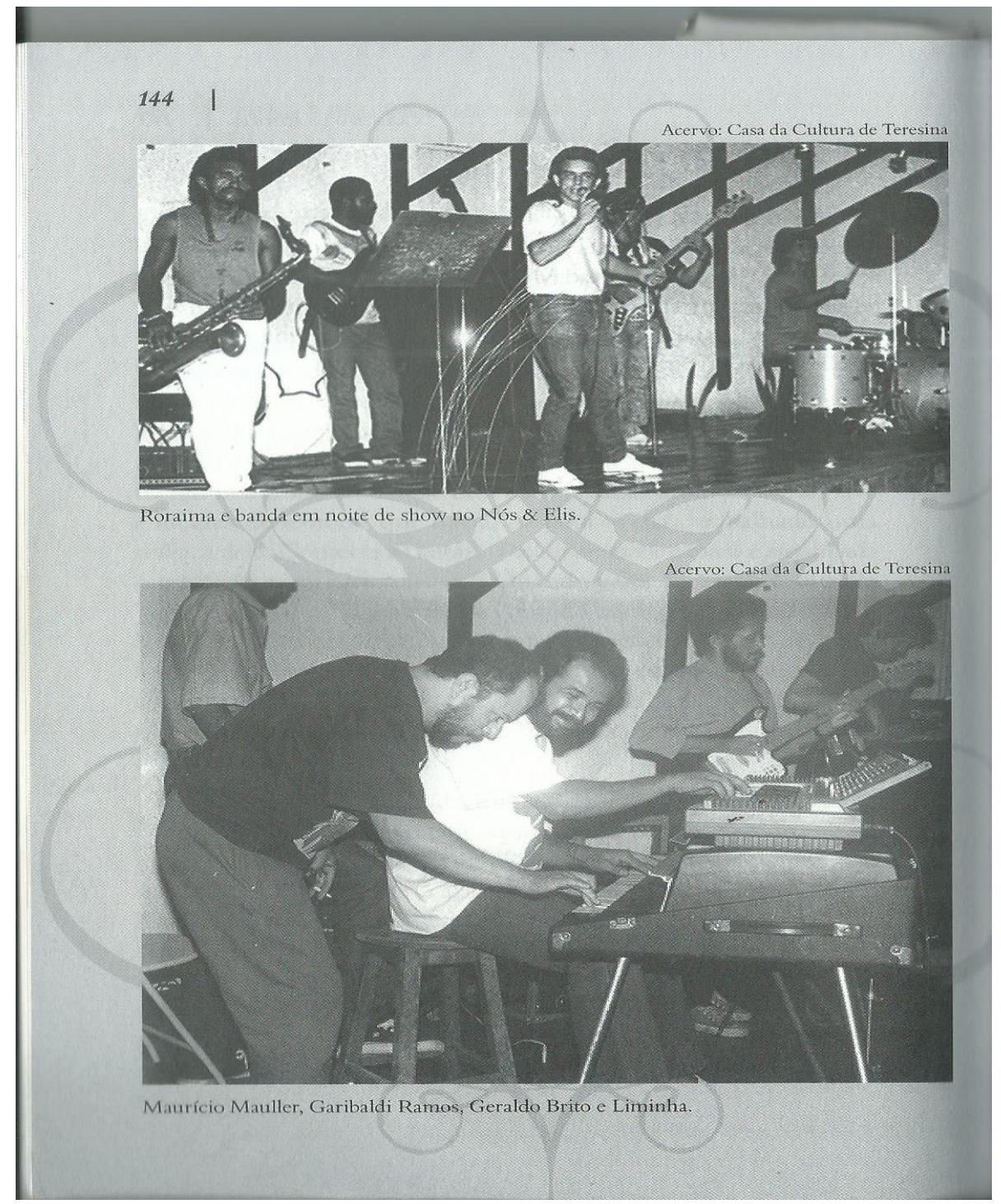


Figuras 3 e 4 - Músicos teresinenses em apresentação no palco do bar Nós e Elis, na década de 1980. Na primeira imagem estão Roraima e banda e, na segunda, os músicos Maurício Mauller, Garibaldi Ramos, Geraldo Brito e Liminha.

(Oeiras, 2010, p. 144).

Esse bar da Zona Leste de Teresina, portanto, era um espaço mágico para uma parcela de seus frequentadores, que apesar de estar localizado numa área que estava se enobrecendo, reunia pessoas de todas as camadas sociais. O seu proprietário, Elias Ximenes do Prado Júnior, fazia questão de tratar bem a todos (Oeiras, 2010). Esta era uma das marcas dessa casa de divertimento que se configurou como um dos principais espaços culturais da cidade devido à importância das atividades ali realizadas e de seus frequentadores, que representavam a síntese da intelligentsia intelectual e artística piauiense.

\section{Considerações finais}

O trabalho apontou a Feira Popular de Arte, o Teatro de Arena, o Verdão e o Auditório Herbert Parentes Fortes, como significativos espaços de lazer e de produção e consumo artístico para um público heterogêneo. Eram espaços públicos cujas atividades eram gerenciadas por organismos municipais e estaduais. As sociabilidades desenvolvidas nesses locais, como degustação de comidas e bebidas típicas, debates, apresentação/apreciação de artesanato e de espetáculos literários, cênicos e musicais. Encontros fraternos e amorosos marcavam esses espaços, imprimindo-lhes uma identidade afetivo-cultural que era reconhecida pelos citadinos. Estes por sua vez, ou pelo menos os sujeitos da nossa pesquisa, acabaram concebendo esses lugares, consciente ou inconscientemente, como "lugares de memória”, no anseio de se preservar essas vivências urbanas (Nora, 1993).

O estudo descreveu ainda as práticas sociais de notívagos nos bares da cidade - tais como o Bar do Cuspe, o Sachas Bar, o Green Bar, o Zeus, o bar Elis Regina e o bar Nós e Elis - que tinham como elemento comum a frequentação de artistas, no palco e/ou na plateia. As várias sociabilidades praticadas nesses lugares, como conversar, comer, dançar, paquerar, eram geralmente acompanhadas pela degustação de bebidas alcoólicas e pela apreciação de uma boa música ao vivo, pelo menos em parte dos bares pesquisados.

Essas casas de divertimento noturno eram espaços privados que ofereciam atividades culturais para o público teresinense e que não se limitavam a sazonalidade dos projetos governamentais. Em nossa pesquisa, eles tiveram destaque nas lembranças de nossos contadores de histórias. Enquanto os espaços públicos 
tinham sua vivência atrelada aos eventos, ofertados geralmente numa periodicidade semanal e mensal, os espaços privados estavam diariamente disponíveis para produção e apreciação artística.

Outro aspecto perceptível em nosso estudo foi que os principais espaços culturais de Teresina estavam localizados na região central da cidade. Entretanto, ficou evidenciado que alguns jovens, especialmente aqueles ligados, direta ou indiretamente, às artes, após a socializaçâo no centro desta urbe se destinavam à zona leste da capital para "completar a noite" no bar Nós e Elis.

Esses espaços, públicos e privados, com ou sem uma sistemática programação artística, constituíam-se como culturais, pelo viés de nossas fontes. E se configuravam como espaços de sociabilidades, onde as interaçóes ocorriam entre as pessoas, bem como entre pessoas e os espaços. Isto é, os citadinos transcendiam a materialidade e se envolviam na sensibilidade urbana que emanava daquelas interaçóes.

\section{Referências}

ABREU, Irlane Gonçalves de; LIMA, Iracilde Maria de Moura Fé. Igreja do Amparo: o marco zero de Teresina. In: Cadernos de Teresina. Teresina, ano 12, n. 32, p. 20-25, out. 2000 .

ALBERTI, Verena. O que documenta a fonte oral: a ação da memória. In: Ouvir contar: textos em história oral. Rio de Janeiro: Editora FGV, 2004. p. 33-43.

ARAÚJO, José Luís Lopes (Coord.). Atlas escolar do Piauí: geo-histórico e cultural. João Pessoa: Grafiset, 2006.

BOSI. Ecléa. Sugestôes para um jovem pesquisador. In: O tempo vivo da memória: ensaios de psicologia social. São Paulo: Ateliê Editorial, 2003. p. 59-67.

FAÇANHA, Antônio Cardoso. Desmistificando a geografia: espaço, tempo e imagens. Teresina: EDUFPI, 2004.

FREITAS, Sônia Maria de. História oral: possibilidades e procedimentos. São Paulo: Humanitas/ FFLCH/ USP; Imprensa Oficial do Estado, 2002.

LIMA, Jurandir Gonçalves. Entre favelas e arranha céus: Teresina, poder e política habitacional no último "quartel" do século XX. In: SANTOS, Raimundo Nonato 
Lima dos (Org.). As cidades de Clio: abordagens históricas sobre o urbano. Teresina: EDUFPI, 2014. p. 277-295.

MEDEIROS, Hermano Carvalho. A cidade e a música popular: Teresina e os espaços de prática musical nos anos 1980. In: SANTOS, Raimundo Nonato Lima dos (Org.). As cidades de Clio: abordagens históricas sobre o urbano. Teresina: EDUFPI, 2014. p. 167-184.

MOURA, Paulo. [Encontro de amigos/artistas no bar Nós e Elis, em Teresina, em 1986. Na primeira foto estão o cartunista Paulo Moura, Lêda Guimarães, os cantores Fátima Lima e Rubens Lima. Na segunda foto estão o cantor Rubens Lima, o cartunista Paulo Moura, o pintor Nonato Oliveira, a cantora Fátima Lima e Mimita]. In: Paulo Moura humor e artegrafia. Memória p\&b 6 e 2. Disponível em: <http://paulomourateresina.blogspot.com/2008/12/>. Acesso em: 18 out. 2019. 2 fotografias, $p \& b$.

NASCIMENTO, Francisco Alcides do. A cidade sob o fogo: modernização e violência policial em Teresina (1937-1945). 2 ed. Teresina: EDUFPI, 2015.

NORA, Pierre. Entre memória e história: a problemática dos lugares. In: Projeto História, São Paulo, n. 10, p. 7-28, dez. 1993.

OEIRAS, Joca (Org.). No Nós \& Elis: a gente era feliz - e sabia. Teresina: Halley, 2010.

. [Músicos teresinenses em apresentação no palco do bar Nós e Elis, na década de 1980. Na primeira imagem estão Roraima e banda e, na segunda, os músicos Maurício Mauller, Garibaldi Ramos, Geraldo Brito e Liminha]. In: OEIRAS, Joca (Org.). No Nós \& Elis: a gente era feliz - e sabia. Teresina: Halley, 2010. 2 fotografias, $\mathrm{p} \& b$.

PARQUE vai ter feira de arte. O Dia, Teresina, p. 5, 3 jan. 1984.

PORTELLI, Alessandro. História oral como arte da escuta. São Paulo: Letra e Voz, 2016.

ROTEIRO. Jornal da Manhã. Caderno 2, Teresina, p. 3, 31 jan. 1988.

SAMPAIO, Wellington da Silva. Bar do Cuspe. In: ADRIÃO NETO (org.). Crônicas de sempre. Teresina: Fundação Cultural Monsenhor Chaves, 1994. p. 
$135-136$.

SHOWS. O Dia. Coluna Agite, Teresina, p. 18, 27 jan. 1995.

SHOWS. O Dia. Coluna Sociais, Teresina, p. 20, 29 abr. 1995.

SANTOS, Gervásio; KRUEL, Kenard. História do Piauí. Teresina: Halley / Zodíaco, 2009.

TÔRRES, Gislane Cristiane Machado. Pelas margens: Geração Mimeógrafo no Piauí na década de 1970. Trabalho de Conclusão de Curso (Faculdade de História) - UFPI, Teresina, PI, 2007

VANESSA, Mara; IGLESIAS, Diego. Pequenos Espaços, Grandes Ideias - Metal Made in Piauí: Pequenos Espaços, Grandes Ideias. In: Portalodia.com. Distorção. 13 out. 2010. Disponível em: <https://www.portalodia.com/blogs/distorcao/pequenos-espacos-grandes-ideias-91640.html>. Acesso em: 17 out. 2019.

WAGNER, Marcos; FEIJÓ, Leo. Rio cultura da noite: uma história da noite carioca. Rio de Janeiro: Casa da Palavra, 2014.

\section{Fontes orais}

CAMPELO, Francisco Ací Gomes (Ací Campelo) [59 anos]. [maio 2015]. Entrevistador: Raimundo Nonato Lima dos Santos. Teresina, PI, 11 mai. 2015.

CHAVES, Moisés Nunes (Moisés Chaves) [46 anos]. [jun. 2012]. Entrevistador: Raimundo Nonato Lima dos Santos. Teresina, PI, 11 jun. 2012.

CHICO FILHO (Francisco Alves Filho) [46 anos]. [jun. 2012]. Entrevistador: Raimundo Nonato Lima dos Santos. Teresina, PI, 12 jun. 2012.

LEITE, Vera (Verônica Maria Barbosa Lopes) [63 anos]. [ago. 2015]. Entrevistador Raimundo Nonato Lima dos Santos. Teresina, PI, 28 ago. 2015.

LIMA, José Afonso de Araújo. (Afonso Lima) [61 anos]. [set. 2015]. Entrevistador: Raimundo Nonato Lima dos Santos. Teresina, PI, 2 set. 2015. 
MELO, Raimundo Aurélio de (Aurélio Melo) [60 anos]. [jun. 2015]. Entrevistador: Raimundo Nonato Lima dos Santos. Teresina, PI, 12 e 19 jun. 2015.

NASCIMENTO, Edna Maria Magalhães do (Edna Nascimento) [55 anos]. [jun. 2015]. Entrevistador: Raimundo Nonato Lima dos Santos. Teresina, PI, 18 jun. 2015.

NASCIMENTO, Edvaldo [55 anos]. [jun. 2015]. Entrevistador: Raimundo Nonato Lima dos Santos. Teresina, PI, 23 jun. 2015.

SALES, Maria do Rosário (Lari Sales) [59 anos]. [maio 2015]. Entrevistador: Raimundo Nonato Lima dos Santos. Teresina, PI, 15 mai. 2015.

VASCONCELOS, João Batista Sousa (João Vasconcelos) [50 anos]. [maio 2015]. Entrevistador: Raimundo Nonato Lima dos Santos. Teresina, PI, 8 mai. 2015.

Resumo: $\mathrm{O}$ texto tem como objeto de estudo as sociabilidades e sensibilidades urbanas em espaços culturais de Teresina - PI, nas décadas de 1980 e 1990. Analisa, para isso, as práticas sociais desenvolvidas nesses ambientes por artistas teresinenses e avalia a importância desses espaços culturais para os artífices da cidade. A narrativa foi construída com base em variadas fontes, que incluem jornais, crônicas e relatos orais. A análise dessas fontes e a discussão sobre memória e História Oral contou com o aporte teórico de Ecléa Bosi (2003), Sônia Freitas (2002), Verena Alberti (2004) e Alessandro Portelli (2016). O trabalho apontou a Feira Popular de Arte, o Teatro de Arena, o Verdão e o Auditório Herbert Parentes Fortes, como significativos espaços de produção e consumo artístico para um público heterogêneo. Indicou as práticas sociais de notívagos nos bares da cidade, que tinham como elemento comum a frequentaçâo de artistas, no palco e/ou na plateia.

Palavras-chave: Espaços culturais. Sociabilidades. Teresina. História e memória. História e cidade.

\section{Cultural spaces in Teresina (PI): everyday life, memories and sociability (1980 and 1990 decades)}

Abstract: This paper's research subject is the study of the sociability and urban sensibilities in cultural spaces of Teresina (PI), during the 1980 and 1990 decades. For this matter, the social practices developed by teresinenses artists and in these environments are analysed, also the importance of these cultural spaces for the local artisans are evaluated. The narrative was built from a variety of sour- 
ces, including newspapers, chronicles and oral accounts. The analysis of these sources and the discussion about memory and oral history was supported by Ecléa Bosi (2003), Sônia Freitas (2002), Verena Alberti (2004) and Alessandro Portelli (2016). The study pointed out the Popular Art Fair, the Arena Theater, the Verdão and the Herbert Parentes Fortes Auditorium as significant spaces for artistic production and consumption for a heterogeneous audience. It indicated the social practices of night owls in the town's bars that had as common element the attendance of artists, on stage and/or in the audience.

Keywords: Cultural spaces. Sociability. Teresina. History and memory. History and city.

Recebido em 10/08/19

Aprovado em 21/10/19 